\title{
EFFECT OF PRECURSORS FEEDING AND MEDIA MANIPULATION ON PRODUCTION OF NOVEL ANTICANCER PRO-DRUG CAMPTOTHECIN FROM ENDOPHYTIC FUNGUS
}

\author{
Touseef Amna ${ }^{1,2 *}$, Musarat Amina ${ }^{2}$, P.R. Sharma ${ }^{1}$, S.C. Puri ${ }^{1}$, Hanan M. Al-Youssef ${ }^{2}$, Areej M. Al-Taweel ${ }^{2}$, G. N. Qazi ${ }^{1}$ \\ ${ }^{1}$ Indian Institute of Integrative Medicine (Formerly Regional Research Laboratory), Canal Road, Jammu Tawi- 18001, India; \\ ${ }^{2}$ Department of Pharmacognosy, College of pharmacy, King Saud University, Riyadh, 11451, Saudi Arabia.
}

Submitted: June 24, 2010; Returned to authors for corrections: March 21, 2012; Approved: June 07, 2012.

\begin{abstract}
We have established methodology for the isolation and characterization of a novel endophytic fungus from the inner bark of medicinal plant Nothapodytes foetida, which produced camptothecin in Sabouraud broth (SB) under shake flask conditions. Camptothecin and its related compounds are at present obtained by extraction from intact plants, but fungal endopytes may be an alternative source of production. In present study we have observed the effect of different nutrient combinations and precursors (tryptophan, tryptamine, geraniol, citral, mevalonic acid and leucine) on the accumulation of camptothecin by endophytic fungus Entrophospora infrequens. The precursors were fed either alone or in combinations (tryptophan and geraniol, tryptophan and citral, tryptophan and mevalonic acid, tryptophan and leucine). The highest camptothecin content was observed in the range of $503 \pm 25 \mu \mathrm{g} / 100 \mathrm{~g}$ dry cell mass in Sabouraud medium. Camptothecin content in the medium was increased by 2.5 folds by the presence of tryptophan and leucine whereas the production with trytophan was also significantly different from other treatments. Furthermore, the effect of fungal camptothecin on the morphology of human cancer cell lines was also studied. The treated cells showed reduction in size, condensation of nucleus and the protoplasmic extensions were reduced. All these characteristics are found in apoptotic cells.
\end{abstract}

Key words: Camptothecin, Entrophospora infrequens, Cancer, Nothapodytes foetida, Precursors

\section{INTRODUCTION}

Camptothecin (CPT) is a monoterpenoid indole alkaloid (Fig. 1a) originally isolated from Camptotheca acuminata Decne (47). Various other plant species such as Ophiorrhiza mungo, Ervatomia hyneana and Nothapodytes foetida are also known sources of CPT (1).The supply of this phytochemical depends primarily on the availability of aforesaid plants and mainly on C. acuminata. Many parts of this plant can be used to extract camptothecins (31). CPT is known for its amazing inhibitory action against tumour cells by blocking the eukaryotic topoisomerase-I (48) and also for its activity against the human immunodeficiency virus (HIV) (38). Although a lot is known about the pharmacological effects of CPT and also

*Corresponding Author. Mailing address: Indian Institute of Integrative Medicine (Formerly Regional Research Laboratory), Canal Road, Jammu Tawi- 18001, India.; Tel.: +91-191-2569000-10; Fax:+91-191-2569333.; E-mail: touseefamna@gmail.com 
attempts have been made to produce CPT from plant cells and tissue cultures, yet the yield has been low (42). Moreover, the over exploration of this source rendered the plant as an endangered species all over the globe, especially in China. The gene pool of this plant is very small in countries like USA (32). The optimization of culture medium, the supply of biosynthetic precursors and genetic engineering are among the strategies adopted to increase alkaloid production in vitro (46). The production of CPT by endophytic fungi was initially reported by our group in 2005 (39). This important anticancer drug precursor molecule was obtained from endophyte RJMEF001 identified as Entrophospora infrequens". Recently other workers $(25,41)$ have also reported the use of endophytes for the production of camptothecin and its analogues isolated from the hosts Camptotheca acuminata and Nothapodytes foetida respectively. However, there are no published reports of successful industrial scale-ups about this molecule. In continuation of our previous work $(39,2,3,40)$ on microbial chemistry of endophytic culture, herein, we demonstrate the outcome of media manipulations and precursor's treatment on the production of CPT from RJMEF001. Besides, surface culture fermentation (3) studies, solid-state fermentation was also carried out. Additionally, the mechanism of action of fungal CPT on human cancer cell lines was also studied. The HL-60 cells were treated with CPT isolated from the fungal source and the morphology of treated cells was analyzed by electron microscopy. Admittedly the RJMEF001 endophyte is neither a robust nor a high level CPT producer as compared to what was found in host plants. But both the tryptophan and leucine appeared to be useful precursors of CPT to enhance the production in fungal culture-RJMEF001.The present study is only the early step. Nevertheless, the present observation will certainly shed light in optimizing the detailed biosynthetic pathways of such alkaloids by using the labeled precursors in fungal cultures.

\section{MATERIALS AND METHODS}

\section{Collection, identification and authentication of the plant material}

Fresh plant material of $N$. foetida was collected from botanical garden of Indian Institute of Integrative medicine
(IIIM) Jammu. Voucher specimen has been deposited in IIIM Herbarium (Accession no 27002-04). The plant naturally grows in Western Ghats, and was introduced by Dr. S. N. Sharma in the agro-climatic conditions of Jammu (Figure 1b) and authenticated on the basis of botanical characteristics by taxonomist Dr. B.K. Kapahi at IIIM Jammu.

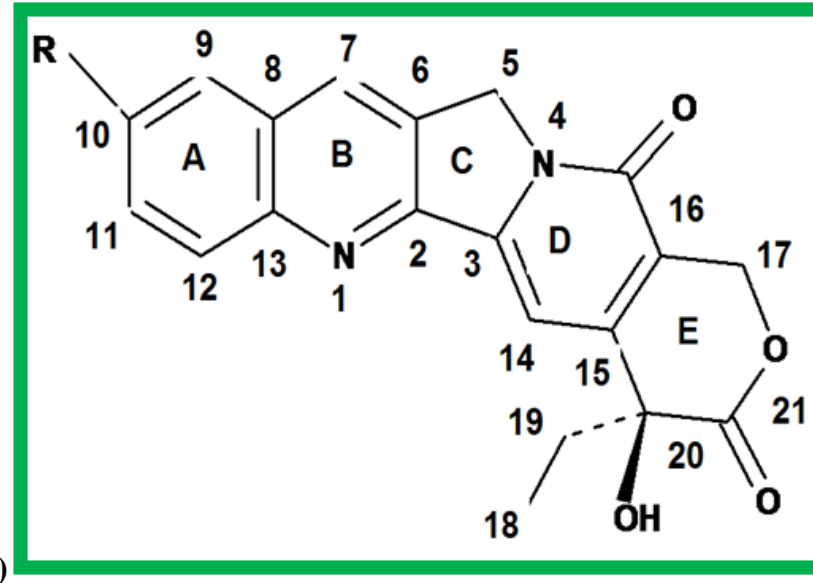

b)

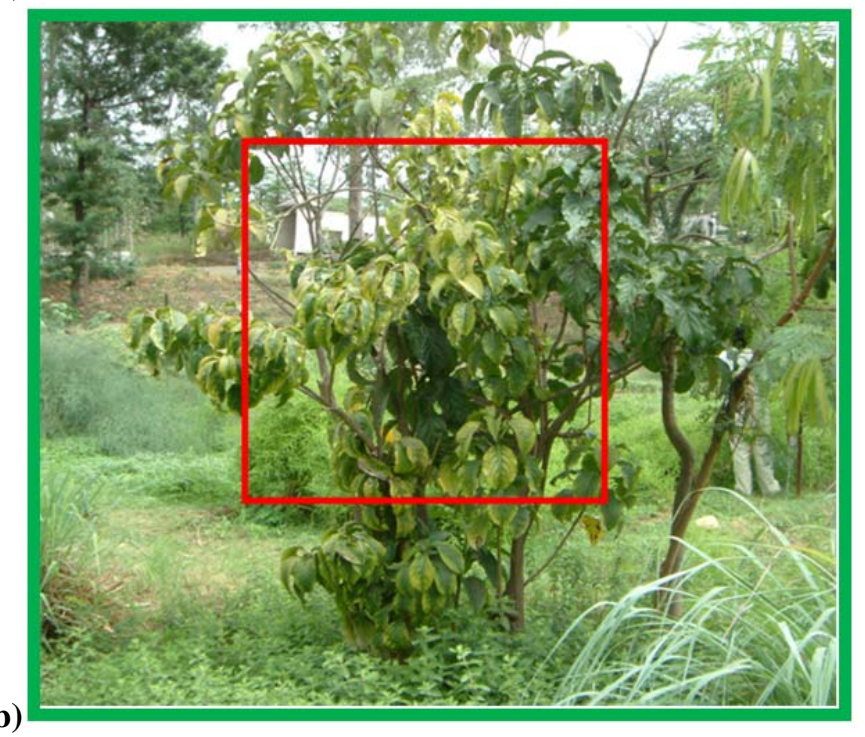

Figure 1. (a) Camptothecin (b) Nothapodytes foetida maintained in botanical garden of Indian Institute of Integrative Medicine Jammu, India.

\section{Isolation and screening of CPT producing endophytes}

The fungal endophytes were isolated using methods described by Arnold et al. (4) and Puri et al. (39). Briefly, small stems explanted from N. foetida plant were surface 
sterilized, rinsed with sterilized distilled water and inner tissues were isolated and placed on aqueous agar in petriplates. At 28 $\pm 2^{\circ} \mathrm{C}$, growth was found to be initiated. The tips of fungal hyphae were placed on mycological medium to obtain pure fungal culture, which was then transferred to a number of solid and liquid media, which supported the fungal growth. To establish the de novo production of CPT by the isolated fungi, the growing mycelia were serially transferred several times to fresh mycological agar to eliminate the possibility of the fungal hyphae carrying even minute amounts of CPT from the host plant material.

\section{Optimization of medium composition for the optimal production of CPT}

For the production of CPT by RJMEF001 culture, spore suspension $\left(10^{5}\right.$ spores $\left.\mathrm{ml}^{-1}\right)$ of the culture was inoculated in Erlenmeyer flasks $(500 \mathrm{ml})$ with different mycological broths
(100 ml). Basic liquid media were Czapek, Malt extract, Molasses, Goos and Tschessch, Potato Dextrose, Ashner and Kohn, Leonine, Bianchi and Sabouraud supplemented with different salts or salts with trace elements and designated as $M_{1}, M_{3}, M_{6}, M_{7}, M_{9}, M_{10}, M_{11}, M_{12}$ and $M_{18}$ respectively throughout in the present study (Table 1). All media were adjusted to $\mathrm{pH} 7.0$ except Sabouraud and Potato Dextrose broth where $\mathrm{pH}$ was maintained 5.6 and 6.0 respectively and were sterilized by autoclaving for $20 \mathrm{~min}$ at $121^{\circ} \mathrm{C}$. The fungal cultures were incubated on a rotary shaker $(220 \mathrm{rpm})$ at $28 \pm$ $2{ }^{\circ} \mathrm{C}$ for $96 \mathrm{~h}$. Different carbon and nitrogen sources like glucose, dextrose, sucrose, maltose, starch, malt extract, yeast extract, peptone, molasses, corn steep liquor, beef extract, urea, ammonium oxalate and ammonium nitrate were added in order to find out the best nutrient combinations for biomass, sporulation and CPT production.

Table 1. Different media used in the present study

\begin{tabular}{|c|c|c|c|}
\hline Liquid media & Code & pH & Composition $\left(\mathrm{gl}^{-1}\right)$ \\
\hline Czapek broth & $\mathrm{M}_{1}$ & 7.0 & $\begin{array}{l}\text { Ammonium oxalate } 3.0 \text {; Potassium hydrogen phosphate } 1.0 \text {; Magnesium sulphate } 0.5 \text {; Potassium } \\
\text { chloride } 0.5 \text {; Ferric sulphate } 0.05 \text {; Sucrose } 30\end{array}$ \\
\hline Czapek broth & $\mathrm{M}_{2}$ & 7.0 & $\begin{array}{l}\text { Dextrose } 30 \text {; Ammonium oxalate } 3.0 \text {; Potassium hydrogen phosphate } 1.0 \text {; Magnesium sulphate } \\
0.5 \text {; Potassium chloride } 0.5 \text {; Ferric sulphate } 0.05\end{array}$ \\
\hline Malt extract broth & $\mathrm{M}_{3}$ & 7.0 & Malt extract 20; Glucose 20; Peptone 1.0 \\
\hline Yeast Beef extract broth & $\mathrm{M}_{4}$ & 7.2 & Yeast extract 1.0 ; Beef extract 1.08 ; Peptone 2.0 ; Ferrous sulphate 0.001 ; Glucose 10 \\
\hline Yeast malt extract & $\mathrm{M}_{5}$ & 7.0 & Malt extract 10 ; Yeast extract 4 ; Magnesium sulphate 0.5 ; Potassium hydrogen phosphate 0.5 \\
\hline Molasses broth & $\mathrm{M}_{6}$ & 7.2 & $\begin{array}{l}\text { Molasses } 7.5 \text {; Sodium chloride } 10 \text {; Calcium sulphate } 0.250 \text {; Corn steep liquor } 20 \text {; Ferrous sulphate } \\
0.160 \text {; Copper sulphate } 0.100 \text {; Magnesium sulphate } 0.500 \text {; Potassium hydrogen phosphate } 0.6\end{array}$ \\
\hline Goose \&Tschessch broth & $\mathrm{M}_{7}$ & 7.0 & Peptone 2; Glucose 10; Magnesium sulphate 0.5 ; Potassium hydrogen phosphate 0.5 \\
\hline Malt extract broth & $\mathrm{M}_{8}$ & 5.4 & Malt extract 30; Peptone 5.0 \\
\hline Potato Dextrose broth & $\mathrm{M}_{9}$ & 6.0 & Diced Potato extract 300; Dextrose 20 \\
\hline Glucose yeast & $\mathrm{M}_{10}$ & 7.0 & Peptone 5; Glucose 20; Difco yeast 2.0 \\
\hline Leonine broth & $\mathrm{M}_{11}$ & 7.2 & $\begin{array}{l}\text { Peptone } 0.625 \text {; Maltose } 6.25 \text {; Malt extract } 6.25 \text {; Potassium hydrogen phosphate } 1.25 \text {; Magnesium } \\
\text { sulphate } 0.625\end{array}$ \\
\hline Bianchi broth & $\mathrm{M}_{12}$ & 7.0 & $\begin{array}{l}\text { Potassium hydrogen phosphate } 1.0 \text {; Potassium nitrate } 1.0 \text {; Magnesium sulphate } 0.55 \text {; Potassium } \\
\text { chloride } 0.5 \text {; Starch } 0.2 \text {; Glucose } 0.2 \text {; Sucrose } 0.2\end{array}$ \\
\hline Czapek broth & $\mathrm{M}_{13}$ & 7.0 & $\begin{array}{l}\text { Dextrose } 30 \text {; Urea 3.0; Potassium hydrogen phosphate 1.0; Magnesium sulphate } 0.5 \text {; Potassium } \\
\text { chloride } 0.5 \text {; Ferric sulphate } 0.05\end{array}$ \\
\hline Czapek broth & $\mathrm{M}_{14}$ & 7.0 & $\begin{array}{l}\text { Sucrose } 30 \text {; Urea } 3.0 \text {; Potassium hydrogen phosphate 1.0; Magnesium sulphate } 0.5 \text {; Potassium } \\
\text { chloride } 0.5 \text {; Ferric sulphate } 0.05\end{array}$ \\
\hline Malt salt broth & $\mathrm{M}_{15}$ & 7.0 & Malt extracts 100; Sodium chloride 100 \\
\hline Malt sucrose broth & $\mathrm{M}_{16}$ & 7.0 & Malt extract 20; Sucrose 200 \\
\hline $\begin{array}{l}\text { Yeast malt extract } \\
\text { dextrose broth }\end{array}$ & $\mathrm{M}_{17}$ & 7.0 & Malt extract 10; Dextrose 4; Yeast extract 4 \\
\hline Sabouraud broth & $\mathrm{M}_{18}$ & 5.6 & Dextrose 40; Peptone 10 \\
\hline Sabouraud broth & $\mathrm{M}_{19}$ & 5.6 & Dextrose 40; Peptone 10; Magnesium sulphate 0.5 ; Potassium dihydrogen orthophosphate 1.0 \\
\hline
\end{tabular}

18-20g of agar per litre was added for the preparation of solid media. 


\section{Extraction of Mycelia}

The fully grown mycelia (after 4 days of incubation) were harvested. The mycelia and broth were separated by filtration and the mycelia were thoroughly washed with sterile distilled water and then homogenized in a cell disintegrator. The resulting homogenates were extracted (3 times) with equal volume of chloroform: methanol $(4: 1 \mathrm{v} / \mathrm{v})$ solvent mixture. The extraction was done thrice and the after stripping off the solvent, residue $(3.9 \mathrm{mg})$ was obtained, a small quantity of the residue was applied on silica gel TLC plates (Merck K GaA, 64271 Darmstadt, Germany).The dried residues were suspended in HPLC grade chloroform: methanol $(9: 1 \mathrm{v} / \mathrm{v})$ solvent mixture.

\section{Effect of precursor molecules on the yield of CPT by RJMEF001}

The endophyte RJMEF001 culture was separately grown in $500 \mathrm{ml}$ Erlenmeyer flasks containing $100 \mathrm{ml} \mathrm{SB}$, each supplemented with different precursor molecules. The incubation temperature was maintained at $28 \pm 2^{\circ} \mathrm{C}$ in a rotary shaker. Fungal culture was fed with precursors namely tryptophan, tryptamine, geraniol, citral, mevalonic acid and leucine. The experiment setup was similar for the elicitation but in addition to that, precursors were fed either alone or in combinations (tryptophan and geraniol, tryptophan and citral, tryptophan and mevalonic acid, tryptophan and leucine). Stock solutions were prepared for each compound and $\mathrm{pH}$ was adjusted to 5.6 before adding to the culture at $0.01 \mathrm{M}$ final concentration except for leucine whose concentration was adjusted at $0.025 \mathrm{M}$. The samples were taken after $96 \mathrm{~h}$. The CPT was extracted as aforementioned. The amount of CPT in each sample was determined by HPLC performed on a reverse phase column (RP-18, $2 \mathrm{~mm}$ i.d., length $150 \mathrm{~mm}$, and particle size $3 \mu \mathrm{m})$. The premixed mobile phase acetonitrile and water $(25: 75 \mathrm{v} / \mathrm{v})$ was run at flow rate of $1 \mathrm{ml} \mathrm{min}^{-1} .10 \mu 1$ of sample was injected in $\mathrm{CHCI}_{3}: \mathrm{MeOH}(9: 1 \mathrm{v} / \mathrm{v})$. For comparison standard CPT was also subjected to HPLC analysis.

\section{Growth and production kinetics of fungal isolate under stationary conditions}

The endophytic fungus RJMEF001 was grown in $500 \mathrm{ml}$ Erlenmeyer flasks, each containing $100 \mathrm{ml}$ liquid SB (Initial $\mathrm{pH}$ 5.6) for 35 days $\left(28 \pm 2^{\circ} \mathrm{C}\right)$ unshaken. Spore suspension with initial count $1 \times 10^{6}$ spores $\mathrm{ml}^{-1}$ was used as inoculum. Sampling was done at regular time intervals (every $7^{\text {th }}$ day). Mycelia and broth were separated and processed as described above in the present study. Both cell homogenates and cell free broth of each culture was extracted and quantified (3). Uninoculated control samples were also processed by usual procedures.

\section{Solid-state fermentation for the production of CPT by RJMEF001}

Solid-state fermentation experiments were carried out on moist wheat bran and wheat bran containing SB. The SB and wheat bran were autoclaved at $121^{\circ} \mathrm{C}$ separately for $35 \mathrm{~min}$ and 15 min respectively. After autoclaving, the wheat bran was mixed with SB aseptically. After cooling, the medium was inoculated with a concentrated spore suspension (10-day old spores, $1 \times 10^{6}$ spores/g dry matter). Initial $\mathrm{pH}$ and moisture content were 5.6 and $70 \%$ respectively. Incubation was carried out at $28+2^{\circ} \mathrm{C}$ for 28 days. Sampling was done at regular time intervals (every $7^{\text {th }}$ day). Fermented material was mixed with equal volume of sterile distilled water and homogenized in a cell disintegrator. The liquid extract was filtered (Whatman no.1) and extracted by normal procedure as mentioned above. Uninoculated control samples were also processed by usual procedures.

\section{Treatment of human cancer cell lines with fungal CPT}

The human cancer cell lines procured from National Cancer Institute, Frederick, U.S.A or National Cancer for Cell Science; Pune, India, were used in present study. Briefly, HL60 cells were grown in tissue culture flasks in complete growth medium (RPMI-1640 medium with $2 \mathrm{mM}$ glutamine, $100 \mu \mathrm{g}$ streptomycin, $\mathrm{pH} 7.4$, sterilized by filtration and supplemented with $10 \%$ fetal calf serum and 100 units $/ \mathrm{ml}$ penicillin before 
use) at $37^{\circ} \mathrm{C}$ in an atmosphere of $5 \% \mathrm{CO}_{2}$ and $90 \%$ relative humidity in a carbon dioxide incubator. The cells at subconfluent stage were harvested from the flask by treatment with trypsin $(0.5 \%$ in PBS containing $0.02 \%$ EDTA). The cells were then seeded into the 96-well tissue culture plate (Becton Dickson and Company, Franklin Lakes, NJ) and allowed to attach and grow in wells overnight before CPT treatment. When HL-60 reached $\sim 40 \%$ confluence, cells were treated with CPT $(5 \mu \mathrm{g})$ dissolved in DMSO. Cell proliferation without drug treatment and with Doxorubicin treatment was set as the controls. In order to ascertain the mechanism of action of fungal CPT on human cancer cell lines, morphological alterations and cell damage were qualitatively investigated using a microscope. Briefly, HL-60 cells were centrifuged at $2000 \mathrm{rpm}$ for $10 \mathrm{~min}$ and were spread over glass slides and allowed to dry in air. The air dried smears were fixed in absolute methanol for $2 \mathrm{~min}$ and stained with Giemsa. The photography was done using Olympus digital camera attached to light microscope (VANOX) and the images were taken at different magnifications.

\section{RESULTS}

\section{Isolation and standardization of RJMEF001 culture}

N. foetida (Mappia foetida; Family: Icacinaceae) was chosen as a source plant for isolating the endophytes, since this plant grows in unexplored environments in the high altitude ranges of Western Ghats, where there is a possibility of mutualistic interactions between different groups of organisms. Earlier studies had indicated that virgin environments favour such interactions (4). The $N$. foetida plant has been reported to be the vital natural source of the camptothecinoids. Fifty two fungal isolates were isolated in the present study. The endophytic fungus (RJMEF001) that was the subject of this study was one of 52 endophytic fungal colonies isolated from inner bark of $N$. foetida. There was considerable variation in colony morphology between isolates, particularly in the shape of the colonies and the amount of aerial mycelium. Many colonies were bran like or convoluted, and / or crusted; aerial mycelium varied from dense cottony to sparse. Nearly all isolates were white, in the beginning but some turned pale brown. Most of the isolates did not sporulate on solid surface and in broth culture. Delayed sporulation was observed in twenty-two isolates out of fifty-two. However, specific sporulation medium (Molasses medium) was used for early and profuse sporulation.

\section{Effect of different media on growth and CPT production}

Various growth media (Table 1) were tried at shake flask level to find the appropriate media for the optimum growth of the organism and CPT production. High CPT production of $503 \pm 25 \mu \mathrm{g} / 100 \mathrm{~g}$ dry cell mass was observed when RJMEF001 was grown in $\mathrm{SB}\left(\mathrm{M}_{18}\right)$ with maximum dry biomass in the range of $14 \pm 1 \mathrm{gl}^{-1}$ (Fig. 2a, b). The CPT production in SB supplemented with trace elements magnesium sulphate $\left(0.5 \mathrm{gl}^{-1}\right)$ and potassium dihydrogen orthophosphate $\left(1.0 \mathrm{gl}^{-1}\right)$, Goos and Tschessch, Leonine and molasses liquid medium was $489 \pm 19 \mu \mathrm{g}, 326 \pm 36 \mu \mathrm{g}, 200 \pm$ $10 \mu \mathrm{g}$ and $230 \pm 25 \mu \mathrm{g} / 100 \mathrm{~g}$ dry cell mass with cell mass of 14 $\pm 1.0 \mathrm{gl}^{-1}, 12 \pm 1.0 \mathrm{gl}^{-1}, 15 \pm 1.0 \mathrm{gl}^{-1}$ and $8 \pm 1.0 \mathrm{gl}^{-1}$ respectively at $96 \mathrm{~h}$ of incubation time. In potato dextrose broth only traces of CPT were detected. Lowest CPT production was observed with Leonine medium. There was no CPT formation in malt extract $\left(\mathrm{M}_{3}, \mathrm{M}_{15}, \mathrm{M}_{16}\right)$, Czapek $\left(\mathrm{M}_{1}, \mathrm{M}_{2}, \mathrm{M}_{13}, \mathrm{M}_{14}\right)$, Ashner and Kohn and Bianchi liquid broths. The highest cell mass of $28 \pm 1.0 \mathrm{gl}^{-1}$ was recorded in Czapek $\left(\mathrm{M}_{14}\right)$ with carbon source Dextrose $(3 \% \mathrm{w} / \mathrm{v})$ and nitrogen source urea $(0.3 \% \mathrm{w} / \mathrm{v})$ and lowest cell mass of $1.84 \mathrm{gl}^{-1}$ in osmotic stress broth with $10 \% \mathrm{NaCl}$ (Fig. 2 b). 


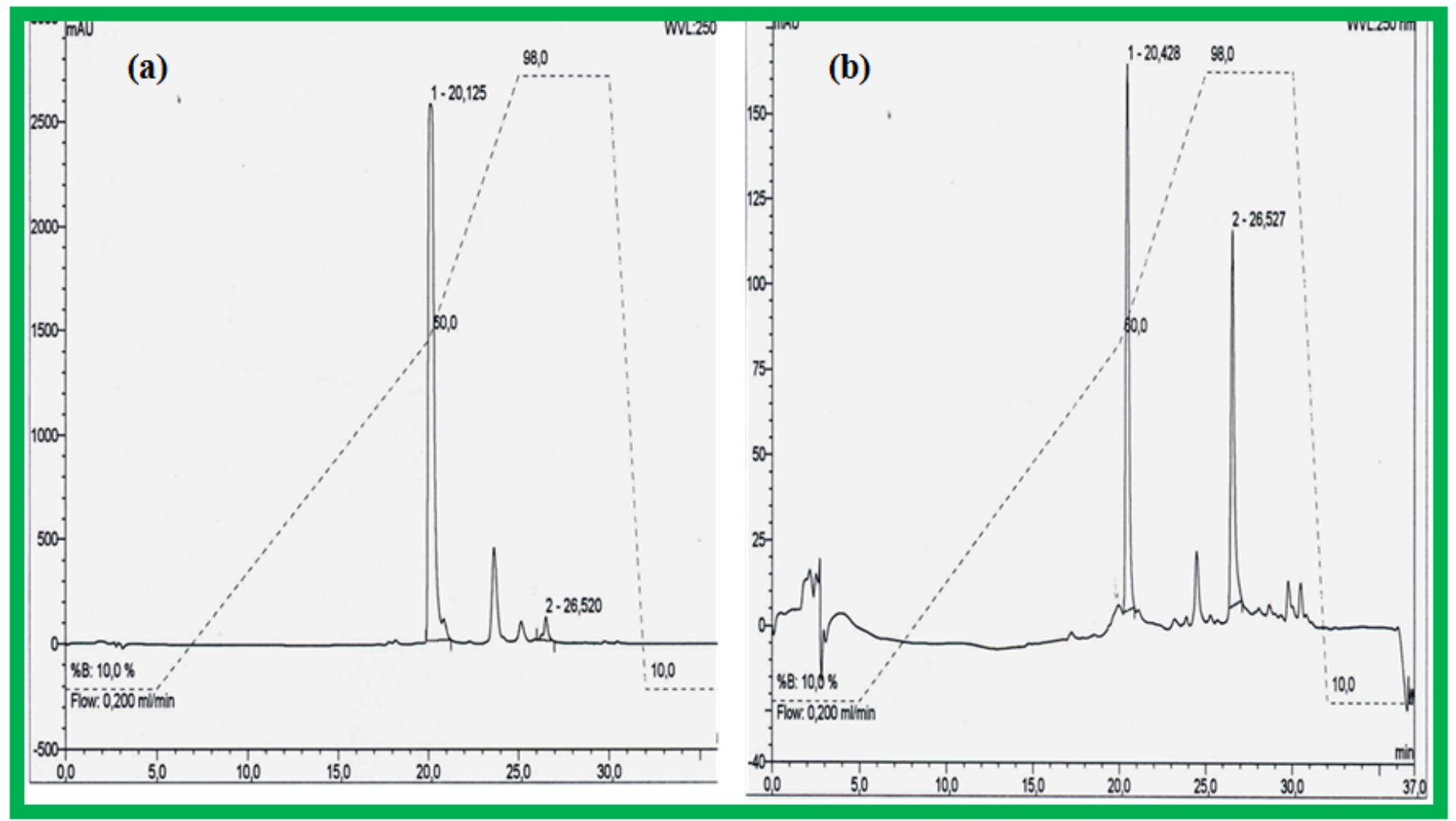

Figure 2. HPLC profile of (a) Authentic Camptothecin (b) Fungal Camptothecin

Effect of carbon and nitrogen sources on the growth and CPT production

RJMEF001 was cultured in the medium containing different carbon, organic and inorganic nitrogen sources to find the conditions leading to the highest production of the CPT. The RJMEF001 isolate grown at shake flask level showed a significant increase $(503 \pm 25 \mu \mathrm{g} / 100 \mathrm{~g}$ dry cell mass $)$ in CPT production in SB when concentration of $1 \%(\mathrm{w} / \mathrm{v})$ peptone was incorporated into the medium. Data represent the mean of three replicates $\pm \mathrm{SD}$, and point-to-point comparison indicates $\mathrm{CPT}$ production at day $96 \mathrm{~h}$. Statistical significance was determined by the unpaired Student's $t$-test. With other nitrogen sources like malt extract, corn steep liquor, beef extract and yeast extract did not show significant increase in CPT production, similarly inorganic nitrogen sources like urea, ammonium oxalate also failed to have any influence on the CPT production. Various sugars when examined as carbon sources at different concentrations $(0.2-4 \%, \mathrm{w} / \mathrm{v})$ failed to show any increase in CPT production. The presence of carbon sources like sucrose and maltose did not produce any significant change in the CPT production profile. There was appreciable decrease in cell mass $\left(3.0 \pm 0.9 \mathrm{gl}^{-1}\right)$ production when culture was grown in the presence of dextrose, sucrose and starch. Eventhough an increase in the cell mass by nine fold was observed when grown in Czapek media. Presence of starch ceased the CPT production and also decreased cell mass production.

\section{Stimulation of the production of CPT by biogenetic precursors and elicitors in fungal culture}

The SB containing geranial $(0.01 \mathrm{M})$, citral $(0.01 \mathrm{M})$, precursors and tryptophan $(0.01 \mathrm{M})$, in combination with geranial $(0.01 \mathrm{M})$ and citral $(0.01 \mathrm{M})$, showed good cell growth without production of desired metabolite but CPT production was observed when the fungal culture was grown in SB supplemented with tryptophan, tryptamine $(0.01 \mathrm{M})$, mevalonic 
acid $(0.01 \mathrm{M})$ and tryptophan in combination with leucine $(0.025 \mathrm{M})$. However, fungal culture grown in SB supplemented with different precursors and combination of precursors showed no difference in morphology under submerged culture conditions and final $\mathrm{pH}$ was found acidic, which decreased from 5.6 to minimum of 2.5. Less dry biomass production (Fig. 2c) was found in tryptophan and leucine as compared to the other treatments whereas the CPT production (Fig. 2d) with this kind of treatment was also significantly different from other treatments. The idea of using l-leucine was taken from the studies in the biosynthesis of lophocerine where two alternative routes for the biosythesis have been successfully elucidated. Lophocerine is an isoprenyl alkaloid. It has been clearly observed that leucine can be substitute for the isoprenyl pyrophosphate, which in turn is generated from mevalonic acid (15).

\section{Growth and production kinetics of fungal isolate under}

\section{stationary conditions}

The mycelial mat formation started after 3 days of incubation time and complete mycelial mat formation was observed at $8^{\text {th }}$ day. The maximum mycelium was found to be $16 \pm 0.94 \mathrm{gl}^{-1}$ at $7^{\text {th }}$ day, which increased during the course of incubation period and peaked $\left(22 \pm 0.80 \mathrm{gl}^{-1}\right)$ at 21 days. The $\mathrm{pH}$ of the medium decreased from 5.6 to minimum of 4.5 (Fig. 3a). CPT was followed as a function of time in still culture. The mycelia and broth extracts of fungus were found to accumulate CPT in trace amounts after 7 days of incubation period. The CPT peaked at 21 days of incubation and rapidly declined after 28 days (Fig. 3b), however the biomass continued to grow. The maximum yield of CPT was found to be $3.0 \pm 0.44 \mathrm{mg}$ per $100 \mathrm{~g}$ dry weight and was $250 \pm 20 \mathrm{gl}^{-1}$ of broth. No CPT formation was observed in uninoculated culture broths and in inoculated, extracted and processed culture broths at zero time (Fig. 3c, d).

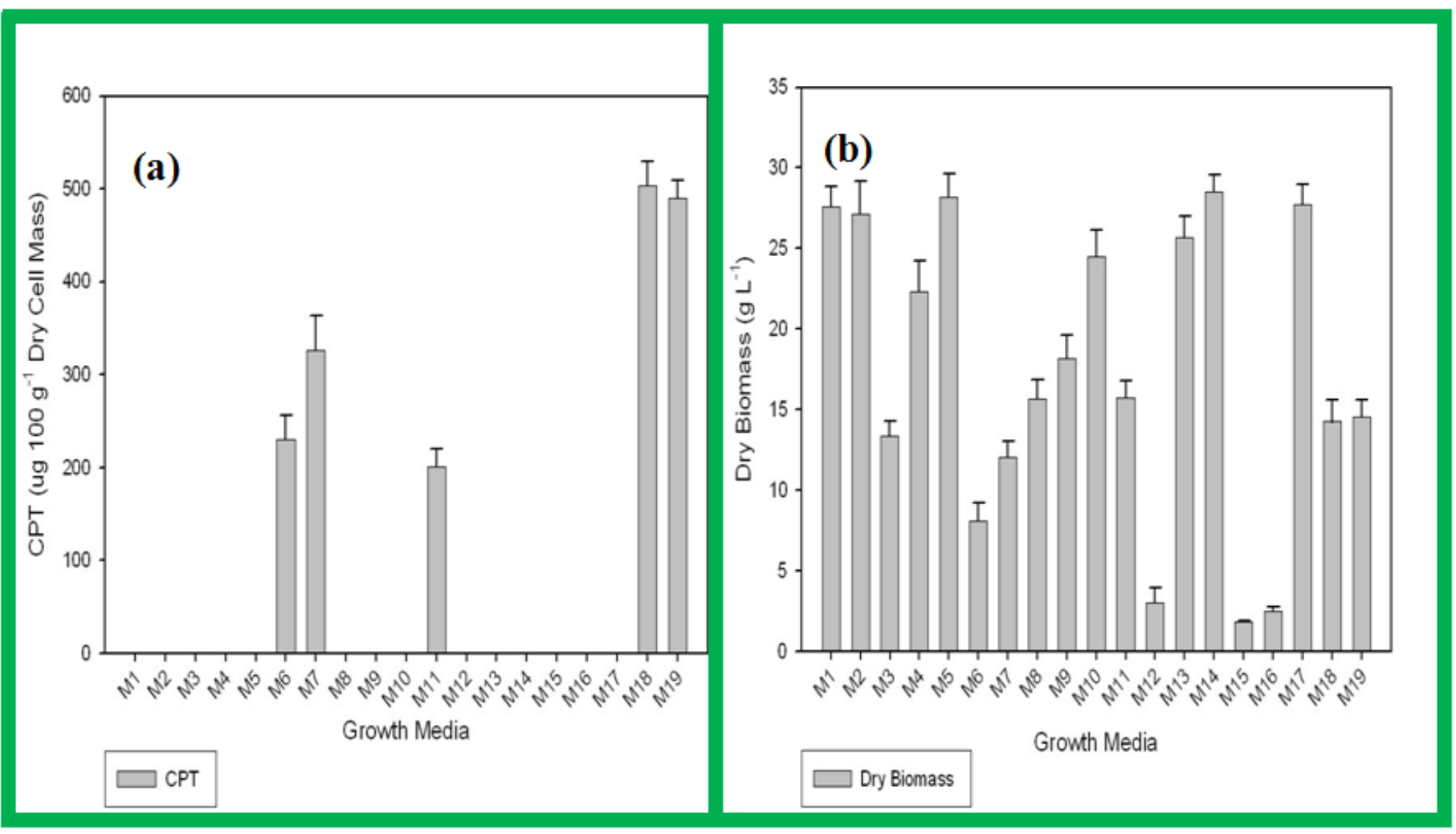




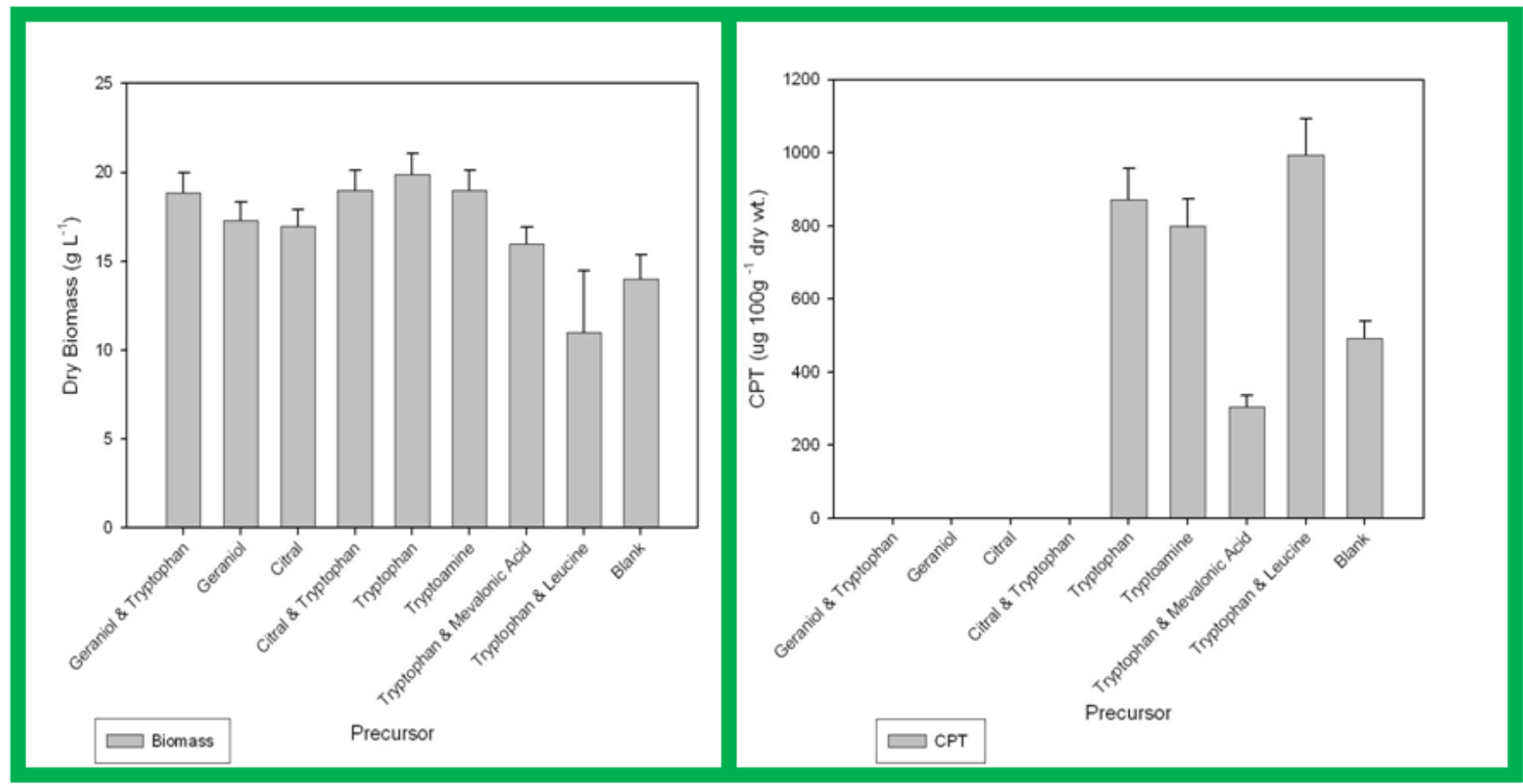

Figure 3. (a) CPT and (b) Biomass production by RJMEF001 culture on various mycological broths under submerged conditions (c) Biomass and (d) CPT production by RJMEF001 culture in Sabourad broth supplemented with different precursors under submerged conditions. CPT was isolated and quantified and the mycelium was harvested, dried and weighed. Values are triplicate determinations and SD of experiments

\section{Solid-state fermentation}

Solid state fermentation (SSF) using inert supports impregnated with chemically defined liquid media has several potential applications in both studies and in the industrial production of high value products, such as metabolites, biological control agents and enzymes. In the present study, the solid-state fermentation was carried out on moist wheat bran and wheat bran supplemented with SB. The fungal mycelia emerged out after 2 days of incubation time and showed complete white cottony mat formation after $96 \mathrm{~h}$ of incubation period. The initiation of sporulation was observed at $8^{\text {th }}$ day of incubation. The flasks were harvested at zero, 7, 14, 21 and 28 days and processed. The CPT production started at $7^{\text {th }}$ day and the maximum yield of $200 \pm 20 \mu \mathrm{g} / 100 \mathrm{~g}$ dry weight and $390.78 \pm 20 \mu \mathrm{g} / 100 \mathrm{~g}$ dry weight on wheat bran and wheat bran supplemented with SB respectively was observed at 21 days (Fig. 4a), thereafter decline in the production was observed.
However the maximum biomass of $13 \pm 1.0 \mathrm{gl}^{-1}$ and $14 \pm 1.0$ $\mathrm{gl}^{-1}$ (Fig. 4b) on wheat bran and wheat bran supplemented with sabouraud broth respectively was observed at 14 days (Fig. 4d, e).

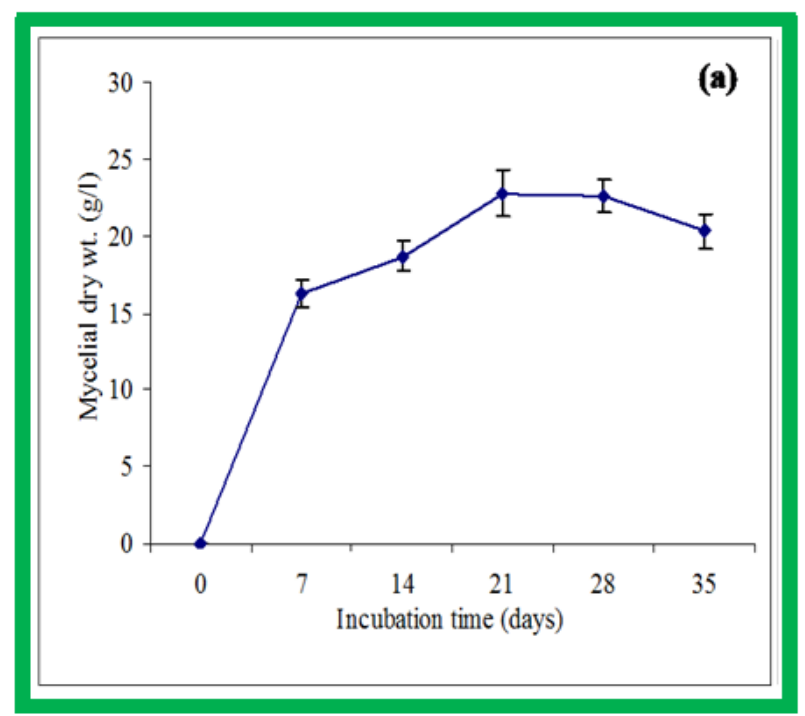




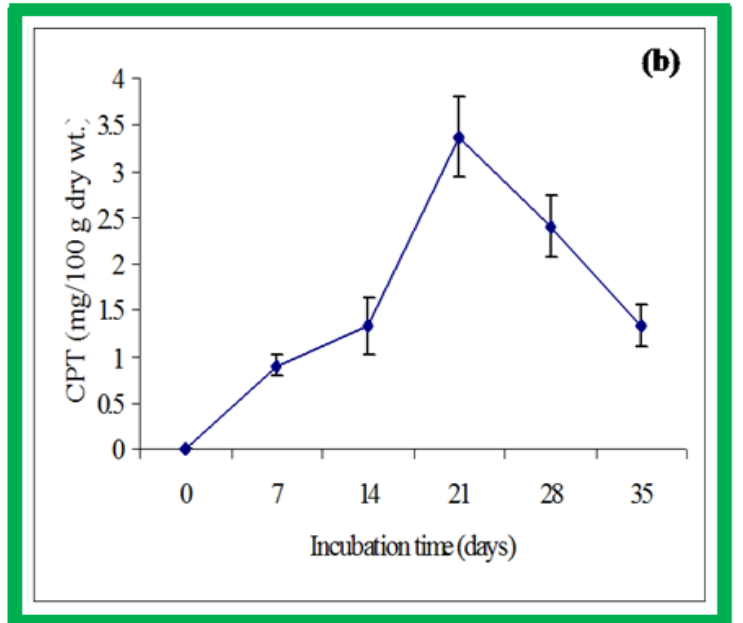

(c)

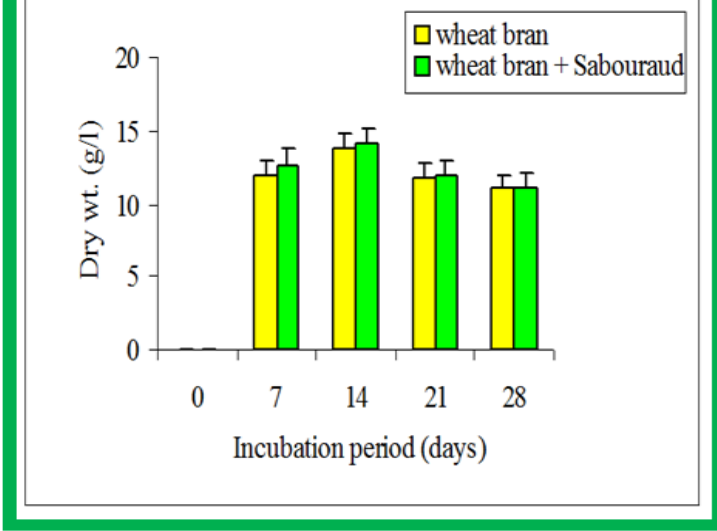

(d)

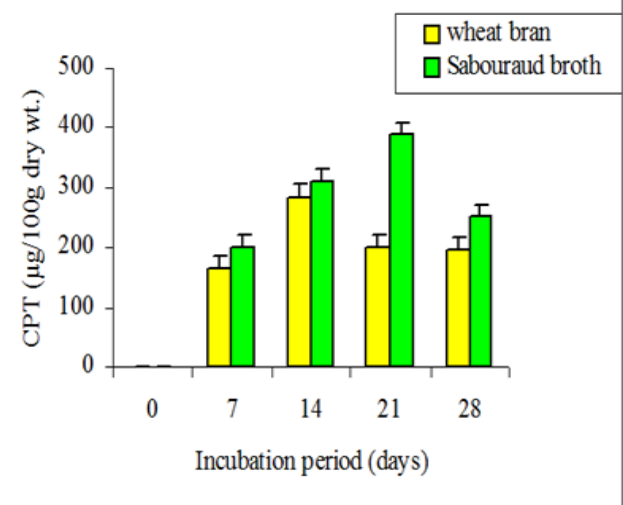

Figure 4. (a) Mycelial dry weight (b) CPT production by RJMEF001 culture as a function of time in still culture (c) Production profile of RJMEF001 (d) Growth profile of RJMEF001 on wheat bran and wheat bran supplemented with Sabouraud broth. Data represents mean of three replicates \pm SD. CPT was isolated and quantified and the mycelium was harvested, dried and weighed. Each weekly point is the mean of four determinations $\pm \mathrm{SD}$

\section{Effect of fungal CPT on morphology of human cancer cell} lines

In order to study the mechanism of action of CPT on human cancer cell lines, the light microscopic studies of untreated and CPT treated HL-60 were done. The untreated HL-60 cells are spherical in shape and have large sized nuclei leaving cytoplasm only to the periphery (Fig. 5a b). After treatment, the cell showed apoptotic morphology such as reduction in size, condensation of nuclei and vacuolization of cytoplasm (Fig. 5c d). The nuclear fragmentation was also seen (Fig. 5e f). The treated cells showed reduction in size, condensation of nucleus and the protoplasmic extensions were reduced. All these characteristics are found in apoptotic cells.

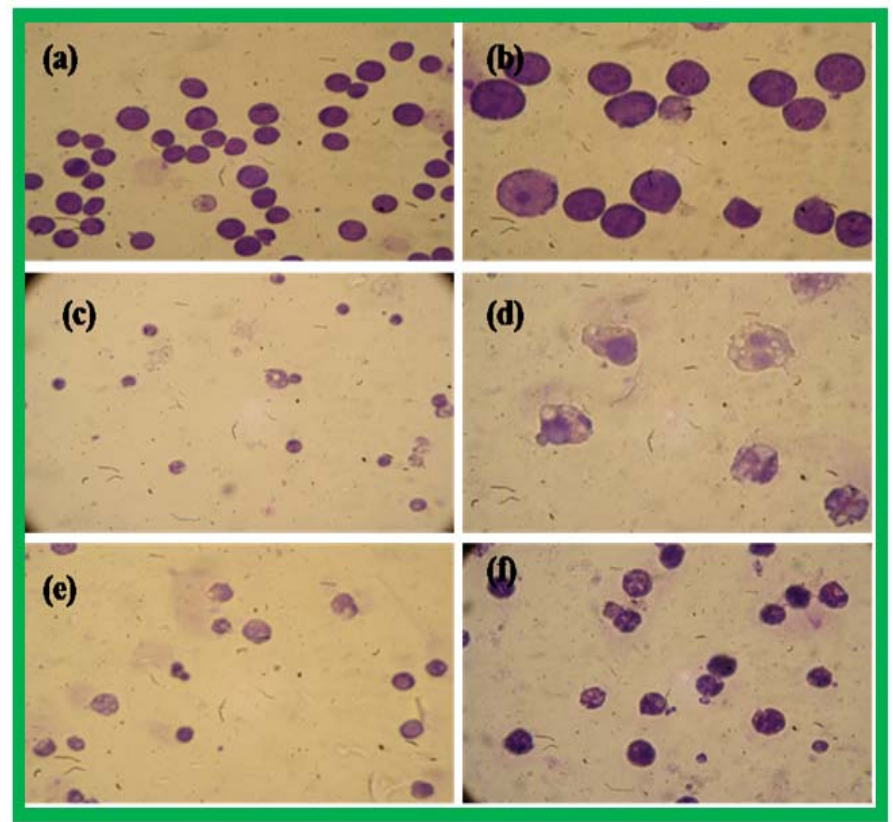

Figure 5. (a, b) Untreated HL-60 Cells, (c-d) Doxorubicin treated HL-60 cells $\left(1 \times 10^{-5} \mathrm{M}\right)$ show condensation of cytoplasm and nucleus, (e-f) CPT treated HL-60 cells also show condensation of cytoplasm and nucleus. (a, c and e Mag. 450X, b, d and $\mathrm{f}$ Mag.900X)

\section{DISCUSSION}

The selected organism identified as E. infrequens by LSU 
rDNA typing hitherto reported as ectomycorrhizal fungi. The search for $N$. foetida associated microbes that produce CPT is justified by previous examples of plant associated microbes producing plant compounds, such as gibberellin (43). The pathways of gibberellins biosynthesis in the fungus and the higher plant are identical up to $\mathrm{GA}_{12}(26)$. Each one of the five classes of plant hormones (auxins, abscisins, ethylene, gibberellins and kinetins) is, in fact, known from a wide range of representative plant-associated fungi and bacteria (18). We reported for the first time, the production of quinoline alkaloid CPT by an endophytic fungus (RJMEF001) (39). Microorganisms often produce secondary metabolites in response to environmental stress or nutrient availability. Stress can be chemically induced by physico-chemical manipulations, which can result in the production of unique metabolites not ordinarily associated with a particular microorganism. Both unusually high and low levels of particular nutrients can alter fungal metabolism. These chemical stresses can result in highly reproducible yields of unusual natural products. Endophytic fungi offer a unique opportunity for media alteration because endophytes may metabolize certain classes of nutrients produced by their hosts. Removal from the host can alter secondary metabolite production, so the addition of host by products may be equally effective. This metabolic response to specific chemical cues is bioenergetically sound. Varying the fermentation protocols in the synthetic media can also greatly affect the production and diversity of secondary metabolites. Adding high levels of one nutrient or trapping another nutrient may result in substantial differences in secondary metabolite production. (44). Productivity amplification is relatively easy in microorganisms. In the case of penicillin, improved culture conditions and genetic manipulation of developing strains of penicillium increased drug yield from a few micrograms per milliliter to thousands of micrograms per milliliter $(14,19)$. Different bioactive compounds can be produced by altering culture conditions. The antibiotic aplasmomycins was produced by Streptomyces griseus SS-20 only after the addition of $\mathrm{NaCl}$ to the medium (36). Directed changes in the culture conditions can be explored indefinitely as a means of optimizing biosynthetic pathways that may lead to even more effective analogues (37). With this background, in the present study, the production of secondary metabolite (CPT) from endophyte- RJMEF001 in response to the media manipulation was examined. SB was found to be the best medium, among the various growth media tried for the production of CPT. After optimizing the medium for the best possible CPT production, stimulation of the production of pentacyclic alkaloid CPT by biogenetic precursors and elicitors in fungal culture was studied. Alkaloids form one of the most widely studied groups of plant secondary metabolites; over 12000 alkaloids have been characterized from the plant kingdom (17). Tryptophan $(28,24,23)$, tryptamine $(24,9,5)$, mevalonate $(30,34,7,21,35)$, geraniol $(21,8,33,29,16)$, loganin $(11,6)$, secologanin (10) and vincoside (9,5), have already been established as precursors of CPT type of indole alkaloids. Sheriha and Rapoport (42) have shown with their experiments that Tryptophan, mevalonic acid, nerol, and geraniol are incorporated in the biosynthesis of CPT in the plant $C$. acuminata. With the background about the biosynthesis of CPT in plant, fungal culture was fed with the same precursors. Our observations are in variance with their observations. Though tryptophan without any doubt is the main precursor for the synthesis of the alkaloid CPT so far as ring A, B and partly ring $\mathrm{C}$ is concerned (Fig. 1a), however our experiments showed that the incorporation of terpenoid portion of the alkaloid involving ring $\mathrm{D}$ and $\mathrm{E}$ is concerned geraniol, nerol and even surprising mevalonic acid do not appear to be the precursors of the skeleton. Mevalonic acid is an established precursor for the biosynthesis of mono, sesqui and triterpenoids but in the present study incorporation of mevalonic acid did not influence the production of CPT. Our results have shown that tryptophan or tryptamine do enhance the yield of the alkaloid as expected but for the monoterpenoid part of alkaloid our results (Fig. 2d) have shown that leucine $(0.025 \mathrm{M})$ along with Tryptophan $(0.01 \mathrm{M})$ does increase the yield of CPT. This clearly indicates that Leucine is the precursor for the terpenoid portion of the 
alkaloid i.e. ring $\mathrm{D}$ and $\mathrm{E}$ portion of the alkaloid in case of fungal isolate RJMEF001. These experiments open new vistas for the study of biosynthesis of such alkaloids where labeled precursors are to be used for the biosynthesis of fungal metabolites. CPT was produced by endophytic fungus RJMEF001 by surface culture and solid-state fermentation and their physiological and kinetic properties were also studied. The type of culture method used influenced the kinetic and physiological properties. The composition of the production medium is key parameter in optimizing SSF process also because nutritional factors such as the carbon source and the levels of nitrogen and trace metals, can influence the growth and production of metabolites, (20) enzymes, (13) and spores (27). The use of supports impregnated with liquid media offers additional flexibility when designing the medium for the optimal production of metabolites, enzymes and spores. In the present study it was observed that the production under surface culture conditions is approximately nine folds higher than the production by solid-state culture. One of the differences between SSF and surface cultures is that in the former the moisture content of the substrate is low, resulting in a limitation of the growth and metabolism of microorganism. The concept of water availability in a substrate thus becomes very important. The results in this work suggests that culture method (surface culture or solid state) may be responsible for inducing changes in CPT content produced by RJMEF001 isolate. The biological importance of the fungal originated CPT possessing anti-cancer activity was also established, and studied in the present work. The morphological analysis by light and electron microscopy constitutes a very important and even decisive tool to identify the specific type of cell death unambiguously and thus far has been the gold standard for the precise detection of apoptosis based on the original morphological criteria described by Wyllie et al. (50). Interestingly, in the present work, the treated cells showed characteristics which are found in apoptotic cells. Novel agents such as CPT, which target specific molecular pathways, may prove clinically useful in the adjuvant treatment of various cancers. In summary, we report for the first time to the best of our knowledge, the better conditions of production of CPT by an endophytic fungus. CPT and its analogues are naturally occurring group of quinoline alkaloids depicting profound cytotoxic activity (12). Literature survey on CPT revealed that molecule occupies an important position among the plant based anti cancer drugs. In order to conserve the germplasm, a need is felt to look for alternate sources for this class of natural products. The discovery that fungi can bio-synthesize CPT, increasingly lends support to the possibility of horizontal gene transfer between N.foetida and its corresponding endophytic organism. The consistent production of CPT and its analogues by isolate RJMEF001 further supports the theory of Young and co-workers (51) that during the course of evolution, the symbiotic endophytes developed machinery to biosynthesize and tolerate high levels of secondary metabolites in order to better compete and survive in association with the medicinal plant. Further scale-up studies and the analysis of metabolic intermediates to understand the biosynthetic pathway in this particular fungus have already been initiated by our group (Fig. $6)$. 


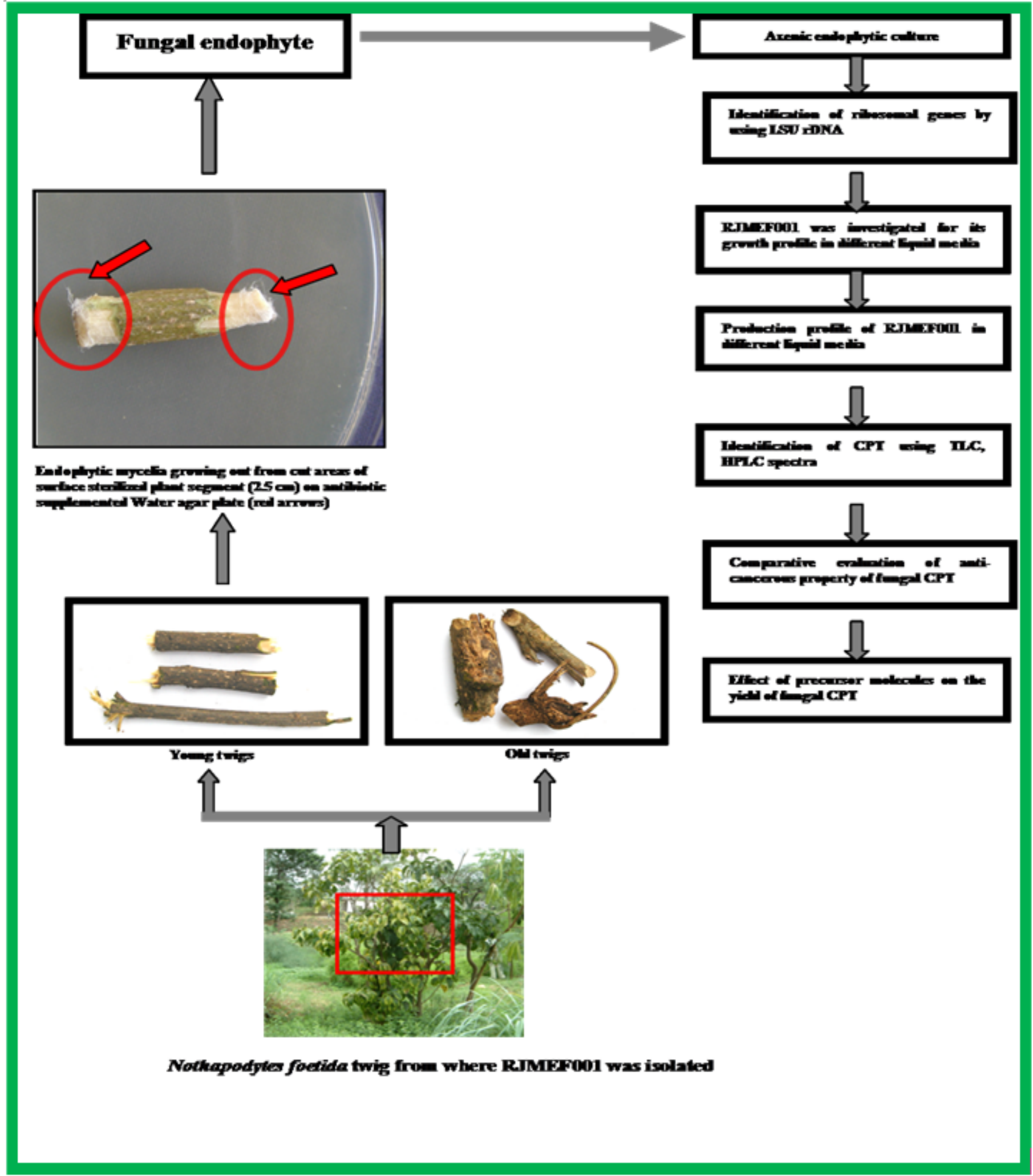

Figure 6. Schematic representation of the experimental strategy adopted for isolation, identification and maintenance of the culture of an endophyte associated with Nothapodytes foetida 


\section{ACKNOWLEDGEMENTS}

We are thankful to Council of Scientific and Industrial Research (CSIR), New Delhi, India for supporting this project.

\section{REFERENCES}

1. Aiyama, R.; Nagai, H.; Kokata, K.; Shinonara, C.; Swada, S. (1988).Camptothecin derivative from Nothapodytes foetida. Photochem. 27, 3663-3664.

2. Amna, T.; Puri, S.C.; Verma, V.; Sharma, J.P.; Khajuria, R.K.; Musarrat, J.; Spiteller, M.; Qazi, G.N. (2006). Bioreactor Studies on the Endophytic Fungus Entrophospora infrequens for the Production of an anticancer alkaloid Camptothecin. Canadian Journal of Microbiol. 52, 189-196.

3. Amna, T.; Khajuria, R.K.; Puri, S.C.; Verma, V.; Qazi, G.N. (2006) Quantification of Camptothecin in an Endophytic fungus by Liquid chromatography-Positive mode Electrospray Ionization Tandem Mass spectrometry (LC-MS/MS). Current Science. 91 (2), 208-212.

4. Arnold, A.E.; Maynard, Z.; Gilbert, G.S.; Coley, P.D.; Kursar, T.A. (2000). Are tropical fungal endophytes hyperdiverse?. Ecol. Lett. 3, 267-274.

5. Battersby, A.R.; Burnett, A.R.; Parsons, P.G. (1969a). Alkaloid biosynthesis. Partial synthesis and isolation of vincoside and isovincoside: biosynthesis of the three major classes of indole alkaloids from vincoside. J Chem Soc Chem Comm. 15, 1193-1200.

6. Battersby, A.R.; Burnett, A.R.; Parsons, P.G. (1970). Preparation and isolation of deoxyloganin: Its role as precursor of loganin and the indole alkaloids. J. Chem. Soc., Chem. Comm. 13, 826.

7. Battersby, A.R.; Brown, R.T.; Kapil, R.S.; Plunkett, A.O.; Taylor, J.B. (1966a). Biosynthesis of the indole alkaloids. Chem. Comm. 2, 46-47.

8. Battersby, A.R.; Brown, R.T.; Knight, J.A.; Martin, J.A.; Plunkett, A.O. (1966b). Biosynthesis of the indole alkaloids from a monoterpene. Chem. Comm. 12, 346-347.

9. Battersby, A.R.; Burnett, A.R.; Parsons, P.G. (1968a). Partial Synthesis and Isolation of Vincoside and Isovincoside: Biosysnthesis of the Three Major Classes of Indoles Alkaloids from the ß-Carboline System. J.Chem. Soc., Chem. Comm. 1282.

10. Battersby, A.R.; Burnett, A.R.; Parsons, P.G. (1969b). Alkaloid Biosynthesis. Part XIV. Secologanin: Its Conversion in Ipecoside and its Role as Biological Precursor of the Indole Alkaloids. J. Chem. Soc. (C), 1187.

11. Battersby, A.R.; Brown, R.T.; Kapil, R.S.; Martin, J.A.; Plunkett, A.O. (1966c) Role of loganin in the biosynthesis of indole alkaloids. Chem. Comm., 23, 890-891.

12. Bodley, J.A.; Cumming, F.N.; Shapiro, T.A. (1998). Effects of camptothecin, a topoisomerase I inhibitor on Plasmodium falciparum. Biochem. Phar. 55,709-711.

13. Christen, P. et al. (1995). Microbial lipase production on a polymeric resin. Biotechnol. Tech. 9, 597-600.

14. Demain, A.L. (1961). Industrial microbiology. Sci. 214, 987-995.

15. Dewick, P.M. (2002). Medicinal Natural Products-A Biosynthetic Approach, second edition;John Wiley \& sons Ltd.England, 321.

16. Escher, S.; Loew, P.; Angoni, D. (1970).The role of hydroxygeraniol and hydroxynerol in the biosynthesis of loganin and indole alkaloids, $J$. Chem. Soc. Chem. Commun. 823-825.

17. Facchini, P.J.; and Bird, D.A.; St-Pierre, B. (2004).Can Arabiodopsis make complex alkaloids. Trends Plant Sci. 9,116-22.

18. Goodman, R.N.; Kiraly, Z.; Wood, R.K.S. (1986).The Biochemistry and Physiology of Plant Disease. University of Missouri Press, Columbia.

19. Grayson, Y. (1982). Antibiotics, Chemotherapeutics and Antibacterial agents for disease control. New York, John Wiley \& Sons.

20. Guttierrez-Rojas, M. et al. (1995). Citric acid and Polyol production by Aspergillus niger at high glucose concentration in solid-state fermentation on inert support. Biotechnol. Lett. 17, 219-222.

21. Hall, E.S.; McCapra, F.; Money, T.; Fukumoto, K.; Hansonm, J.R.; Mootoo, B.S.; Phillips, G.T.; Scott, A.I. (1966). Concerning the terpenoid origin of indole alkaloids: biosynthetic mapping by direct mass spectrometry. Chem. Commun. 12, 348-350.

22. Hall, I.R. (1977). Species and mycorrhizal infections of New Zealand Endogonaceae. Transactions of the British Mycology Soc. 68,341-356.

23. Kutney, J.P.; Beck, J.F.; Nelson, V.R.; Sood, R.S. (1971). Studies on indole alkaloid biosynthesis. VI. The eburnamine-vincamine alkaloids. $J$. Am. Chem. Soc. 93(1), 255-257.

24. Kutney, J.P.; Cretney, W.J.; Hadfeld, J.R.; Hall, E.S.; Nelson V.R.; Wigfield, D.C. (1968). Studies on indole alkaloid biosynthesis. J. Am. Chem. Soc. 90 (13), 3566-3567.

25. Kusari, S.; Zu"hlke, S.; Spiteller, M. (2009). An Endophytic Fungus from Camptotheca acuminata That Produces Camptothecin and Analogues. J. Nat. Prod. 72, 2-7.

26. Lang, A. (1970). Gibberellins: Structure and Metabolism. Annu. Rev. Plant. Physiol. 21, 537-570.

27. Larroche, C. (1996). Microbial growth and sporulation behaviour in solid-state Fermentation. J. Sci. Ind. Res. 55, 408-423.

28. Leete, E. (1961). The incorporation of tryptophan into serpentine and reserpine. Tetrahedron. 14, 1-2.

29. Leete, E.; and Ueda, S. (1966). Biosynthesis of the vinca alkaloids. The incorporation of geraniol-3- ${ }^{14} \mathrm{C}$ into catharanthine and vindoline. Tetrahedron Lett. 4915-4918.

30. Leete, E.; Ghosal, S.; Edwards, P.W.; (1962). Biosynthesis of the NonTryptophan Derived Portion of Ajmaline. J. Am. Chem. Soc. 84, 1068.

31. Li, S.Y.; Adair, K.T. (1994). Camptotheca acuminata Decaisne, Xi, Shu. a Promising Anti-Cancer and Anti-Viral Tree for the $21^{\text {st }}$ Century. A 
Henry M. Rockwell Monograph (ed. Stephen, F.), Austin State University, Texas.

32. Li, S.Y.; Wang, Y.J.; Beasley, R.S.; Northrup, K. (2000). Anticancer happytrees Decaisne Research Report. Arthur Temple College of Forestry, Stephen en F. Austin State University, Texas.

33. Loew, P.; Goeggel, H.; Angoni, D. (1966). A monoterpene precursor in the biosynthesis of indole alkaloids. Chem Commun., 347.

34. McCapra, F.; Money, T.; Scott, A.I.; Wright, I.G. (1965). Biosynthesis of the indole alkaloids: vindoline. Chem. Comm. 537.

35. Money, T.; Wright, I.G.; McCapra, F.; Hall, E.S.; Scott, A.I. (1968). Biosynthesis of indole alkaloids. Vindoline. J.Am. Chem. Soc., 90, $4144-$ 4150 .

36. Okami, Y.; Okazaki, T.; Kitahara, T.; Umezawa, H.J. (1976). Studies on marine microorganisms. A new antibiotic aplasmomycin, produced by a streptomyces isolated from shallow sea mud. J. Antibiot. 32, 1019-1025.

37. Okami, Y. (1986). Marine microorganisms as a source of bioactive agents. Microb. Ecol. 12, 65-78.

38. Priel, E.; Showalter, S.D.; Blair, D.G. (1991). Inhibition of human immunodeficiency virus (HIV-1) replication in vitro by non-cytotoxic doses of camptothecin a topoisomerase -I inhibitor, AIDS Res. Hum. Retroviruses. 7, 65-72.

39. Puri, S.C.; Verma, V.; Amna, T.; Qazi, G.N.; Spiteller, M. (2005). An Endophytic Fungus from Nothapodytes foetida that Produces Camptothecin. J. Nat. Prod. 68 (12), $1717-1719$.

40. Puri, S.C.; Amna, T.; Khajuria, A.; Gupta, A.; Arora, R.; Spiteller, M.; Qazi, G.N., (2008). Immunomodulatory activity of the novel fungal endophyte Entrophospora infrequens isolated Nothapodytes foetida (Wight) Sleumer., Acta. Microbiologica Immunologica Hungarica. 54(3), 237-260.

41. Rehman, S.; Shawl, A.S.; Kour, A.; Andrabi, R.; Sudan, P.; Sultan, P.; Verma, V.;Qazi, G.N. (2008). An Endophytic Neurospora sp. from
Nothapodytes foetida Producing Camptothecin. Applied Biochemistry and Microbiol. 44(2),203-209.

42. Sheriha, G.M.; Rapoport, H.; (1976). Biosynthesis of Camptotheca acuminate alkaloids, Phytochem.15, 505-508.

43. Stowe, B.B.; and Yamaki, T. (1957). The History and physiological action of the Gibberellins, Annu. Rev. Plant. Physiol. 8, 181-216.

44. Tanaka Y. (1992). In: The Search for bioactive Compounds from Microorganisms; Omura S. Ed: Springer-Verlag: New York; 303-324.

45. Van, A.J.; Hengel, M.P.; Harkes, H.J.; Wichers, P.; Hesselink, G.M.; Buitelaar, R.M. (1992). Characterization of callus formation and camptothecin production by cell lines of Camptotheca acuminate. Plant Cell Tissue Org. Culture. 28, 11-18.

46. Verpoorte, R. Van der Heijden, R.; Schripsema, J.; Hoge, J.H.C.; Hoopen, H.J.G. (1993). Plant cell biotechnology for the production of alkaloids: present status and prospects. J. Nat. Prod. 56, 186-207.

47. Wall, M.E.; Wani, M.C.; Cook, C.E.; Palmer, K.H. (1966). Plant Antitumor Agents. I. The isolation and structure of camptothecin, a novel alkaloidal leukemia and tumor inhibitor from Camptotheca acuminata. J. Amer. Chem. Soc. 88, 3888-3890.

48. Wang, J.C. (1985). DNA Topoisomerases. Annu. Rev. Biochem. 54, 665-697.

49. Washo-Stultz, D.; Crowley-Weber, C.L.; Dvorakova, K.; Bernstein, C.; Bernstein, H.; Kunke, K.;Waltmire, C.N.; Garewal, H.; Payne, C.M. (2002). Role of mitochondrial complexes I and II reactive oxygen species and arachidonic acid metabolism in deoxycholate-induced apoptosis. Cancer Lett. 177, 129-144.

50. Wyllie, A.H.; Kerr, J.F.; Currie, A.R. (1980). Cell death: the significance of apoptosis. Int. Rev. Cyt. 68: 251-306.

51. Young, D.H.; Michelotti, E.J.; Sivendell, C.S.; Krauss, N.E. (1992). Antifungal properties of taxol and various analogues. Experientia. 48, $882-885$. 